\title{
Effects of cutting speeds and moisture content on grass chopping (pulverizing)
}

\begin{abstract}
A study was conducted at the Malaysian Agricultural Research and Development Institute, MARDI, Serdang, Selangor, Malaysia, to investigate the effects of Vertical Mower with double sided knife at four different speeds of 2000, 2200, 2500 and $2700 \mathrm{rpm}$, with two grass moisture contents at $20.37 \%$ and $57.07 \%$ wet base (wb\%) during grass chopping (pulverizing). The results obtained showed that all the treatments were significant at 99\% significance level for the percentage of grass leave area and the percentage of length of stem. The best results obtained were at a mower speed of $2500 \mathrm{rpm}$ and $20.37 \%$ of grass moisture content which resulted in average values of $81.03 \%$ for the percentage of the leave area and $82.08 \%$ for the percentage of the length of the stem.
\end{abstract}

Keyword: Chopping; Moisture; Mower; Pulverizer; Slasher; Speed 